\title{
A microestrutura e o desenvolvimento dos órgãos genitais masculinos de preás (Galea spixii) criados em cativeiro ${ }^{1}$
}

\author{
Paulo R.S. Santos ${ }^{2 *}$, Moacir F. Oliveira ${ }^{3}$, Alexandre R. Silva ${ }^{3}$, Carolina Maria \\ O.N. Camargo ${ }^{4}$ e Antônio C. Assis Neto ${ }^{2}$
}

\begin{abstract}
Santos P.R.S., Oliveira M.F., Silva A.R, Camargo C.M.O.N. \& Assis Neto A.C. 2012. [The microstructure and development of male genital organs of Spix's yellow-toothed cavy (Galea spixii) bred in captivity.] A microestrutura e o desenvolvimento dos órgãos genitais masculinos de preás (Galea spixii) criados em cativeiro. Pesquisa Veterinária Brasileira 32(Supl.1):84-90. Setor de Anatomia do Departamento de Cirurgia, Faculdade de Medicina Veterinária e Zootecnia, Universidade de São Paulo, Av. Prof. Dr. Orlando Marques de Paiva 87, São Paulo, SP 05508-270, Brazil. E-mail: pauloramos@usp.br

The Spix's yellow-toothed cavy (Galea spixii) from the Brazilian northeastern semi-arid is a rodent that does belong to the family Caviidae. They are found in regions of the Caatinga and Cerrado, and reproduces throughout the year, with a gestation period of 48 days and a litter of 2 to 4 pups. The aim of this study was to characterize histologically the structural components of the genital organs of male Spix's yellow-toothed cavies regarding their chronological development. For the analysis we used animals at birth and with 15, 30, 45, 60, $75,90,105,120$ and 150 days of age. Fragments of the epididymis, vas deferens, penis and accessory sex glands were collected, fixed and processed for light microscopic. The epididymis had a simple columnar epithelium and at each sexual stage the epididymis was noted different in size of the tubular lumen and regarding the presence of sperm in the lumen at 45 days of age. The epithelium of vas deferens was found to be pseudo-stratified columnar with increasing presence of stereocilia with advancing age. The vesicular gland showed a folded mucosa that varied according to stage of sexual development. The prostate was not very developed, with a small lumen in Spix's yellow-toothed cavy at birth and at 15 days of age; at 45 days showed variable wrinkling of the epithelium. The male genital organs underwent morphological transformations in line with age and sexual development, what helped to determine the onset of puberty, which in the species studied occurred at 45 days of age.
\end{abstract}

INDEX TERMS: Spix's yellow-toothed cavy, Galea spixii, sexual development, rodents, epididymis, vas deferens, accessory sexual glands.

RESUMO.- 0 preá do semiárido nordestino (Galea spixii) é um roedor pertencente à família Caviidae. São encontrados nas regiões da Caatinga e do Cerrado Brasileiro e se reproduz ao longo do ano, apresentando um período de gestação

\footnotetext{
${ }^{1}$ Recebido em 22 de julho de 2012.

Aceito para publicação em 16 de outubro de 2012.

${ }^{2}$ Programa de Pós-Graduação em Anatomia dos Animais Domésticos e Silvestres, Setor Anatomia do Departamento de Cirurgia, Faculdade de Medicina Veterinária e Zootecnia (FMVZ), Universidade de São Paulo (USP), Av. Prof. Dr. Orlando Marques de Paiva 87, São Paulo, SP 05508-270, Brasil. *Autor para correspondência: pauloramos@usp.br

${ }^{3}$ Departamento de Ciências Animais, Universidade Federal Rural do Semi Árido (UFERSA), Campus Central, BR110 Km 47, Mossoró, RN 59625-900, Brasil.

${ }^{4}$ Faculdade de Zootecnia, Universidade Estadual Paulista "Júlio de Mesquita Filho" (Unesp), Campus de Dracena, Rodov. Cmte. João Ribeiro de Barros Km 651, Dracena, SP 17900-000, Brasil.
}

de 48 dias e uma ninhada de 2 a 4 crias. 0 objetivo deste estudo foi caracterizar histologicamente os componentes estruturais dos órgãos genitais de preás machos relacionando com a evolução cronológica destes órgãos na espécie. Foram utilizados para análise animais ao nascimento e aos $15,30,45,60,75,90,105,120$ e aos 150 dias de idade. Fragmentos do epidídimo, ducto deferente, pênis e glândulas sexuais acessórias foram coletados, fixados e processados para descrição em microscopia de luz. 0 epidídimo apresentou epitélio colunar simples e em cada fase sexual notou-se diferença quanto ao tamanho do lúmen tubular e à presença de espermatozóides no lúmen aos 45 dias de idade. 0 epitélio do ducto deferente no preá mostrou-se pseudo-estratificado colunar com crescente presença de estereocilios com o avanço da idade. A glândula vesicular no preá apresentou uma mucosa com pregueamento va- 
riado, de acordo com a fase do desenvolvimento sexual. A próstata mostrou-se pouco desenvolvida, com lúmen pequeno nos preás ao nascimento e aos 15 dias de idade; aos 45 dias mostrou-se com um pregueamento do epitélio variável. Os órgãos genitais masculinos do preá passaram por transformações morfológicas no decorrer da idade e com o desenvolvimento sexual, isso colaborou para a determinação do início da fase da puberdade, que na espécie em estudo foi aos 45 dias de idade.

TERMO DE INDEXAÇÃO: Preás, Galea spixii, desenvolvimento sexual, roedores, epidídimo, ducto deferente, glândulas sexuais acessórias.

\section{INTRODUÇÃO}

0 preá (Galea spixii) é um roedor pertencente à família Caviidae. São encontrados nas regiões do Semiárido, Caatinga e Cerrado do Nordeste brasileiro (Santos et al., 2011). Têm hábito crepuscular, vivendo em bandos e alimentando-se de folhas, ramos e frutos de plantas rasteiras (Mendes, 1987). Possui comprimento de 22,5 a 23,5cm e pesam entre 375 e $405 \mathrm{~g}$ e um anel de pêlos brancos ao redor dos olhos. É um animal que se reproduz ao longo do ano, apresentando um período de gestação de 48 dias e uma ninhada de 2 a 4 crias (Eisenberg \& Redford 1999, Oliveira et. al. 2008). O preá vem sendo criado em cativeiro, com o intuito de fornecer fonte alternativa de proteína animal, preservar a espécie e proporcionar o desenvolvimento de pesquisas (Santos et al., 2011). Estudos relacionados à reprodução de preás machos resumem ao estabelecimento da espermatogênese na fase puberal aos 45 dias de idade (Santos et al. 2012).

Os órgãos genitais masculinos dos roedores são compostos pela via espermática e pelas glândulas acessórias. Durante o processo ejaculativo, os espermatozóides armazenados no epidídimo seguem para os ductos deferentes, onde as glândulas sexuais acessórias irão atuar na composição química e no volume do sêmen (Chaves et al. 2011) percorrendo pela uretra e pênis. Estudos da via espermática e das glândulas acessórias foram vistos no rato gigante da Índia (Amiya \& Maiti1982), na capivara (Paes de Barros et al. 2000), viscacha (Chaves et al. 2011), no hamster dourado (Nicander \& Glover 1973), no coelho (Nicander 1956), na cobaia (Hoffer \& Greenberg 1978), na paca (Borges 2004, Matamoros 1981) e na cutia (Mollineau et al. 2009, Menezes et al. 2010); entretanto, não há relatos descritivos dos órgãos genitais no preá. Considerando a carência de estudos sobre a biologia reprodutiva da espécie este trabalho objetivou descrever a cronologia do desenvolvimento dos órgãos genitais masculinos do preá sob o ponto e vista histológico.

\section{MATERIAL E MÉTODOS}

Para a caracterização histológica dos órgãos genitais masculinos, fragmentos do epidídimo, ducto deferente, pênis, glândula vesicular, glândula bulbouretral e próstata de preás ao nascimento e aos $15,30,45,60,75,90,105,120$ e aos 150 dias de idade foram coletados no Centro de Multiplicação da Universidade Federal Rural do Semi Árido, Mossoró, RN (Projeto FAPESP 08/57190-8, Comissão de Ética no 009/2008 e autorização IBAMA no 2028236/2008) e fixados em Bouin e Paraformoaldeído, por um período de no mí- nimo 12 horas. As amostras foram lavadas em álcool 70\%, para remoção do excesso de fixador, seguindo de desidratação em uma série crescente de álcoois em concentrações de 70 a 100\%, diafanizados em xilol e incluídos em parafina (Sigma, Oxford, MS, USA). Foram realizados corte de $5 \mu \mathrm{m}$ de espessura, obtidos com micrótomo Leica e as amostras coradas por Hematoxilina-Eosina (HE). A coleta do material, os cortes histológicos, bem como, a preparação e coloração das lâminas foram realizadas com base na metodologia descrita por (TOLOSA et al. 2005). As estruturas foram denominadas com base no que preconiza o International Committee on Veterinary Histological Nomenclature (1994).

\section{RESULTADOS}

No preá foi verificado que os órgãos genitais estão localizados na cavidade pélvica e são representados por um par de testículos; um par de epidídimos, compostos por cabeça, corpo e cauda; ducto deferente; glândulas sexuais acessórias: vesicular, próstata e bulbouretral; uretra; pênis e prepúcio (Fig.1).

Epidídimo. No epidídimo do preá foi verificado que o ducto epididimário possuía epitélio colunar simples apoiado em tecido conjuntivo frouxo (Fig.2D). A população celular do epitélio de revestimento do epidídimo do preá é formada principalmente pelas células principais e basais. 0 tipo celular predominante, as células principais, são células cilíndricas localizadas entre a membrana basal e o lúmen tubu-
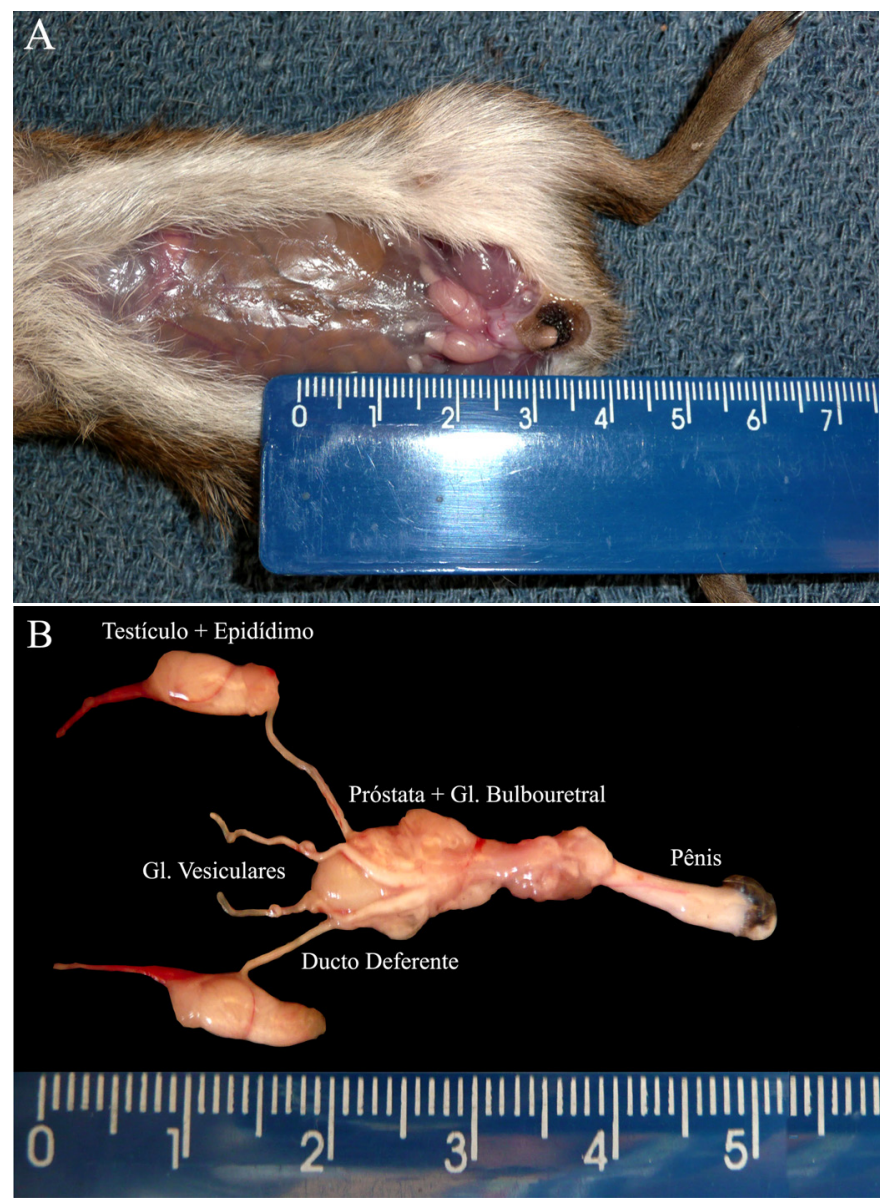

Fig.1. (A) Os órgãos genitais masculinos do preá aos 15 dias de idade mostram-se dispostos na cavidade pélvica. (B) Observa-se as estruturas do órgão genital masculino do preá. 


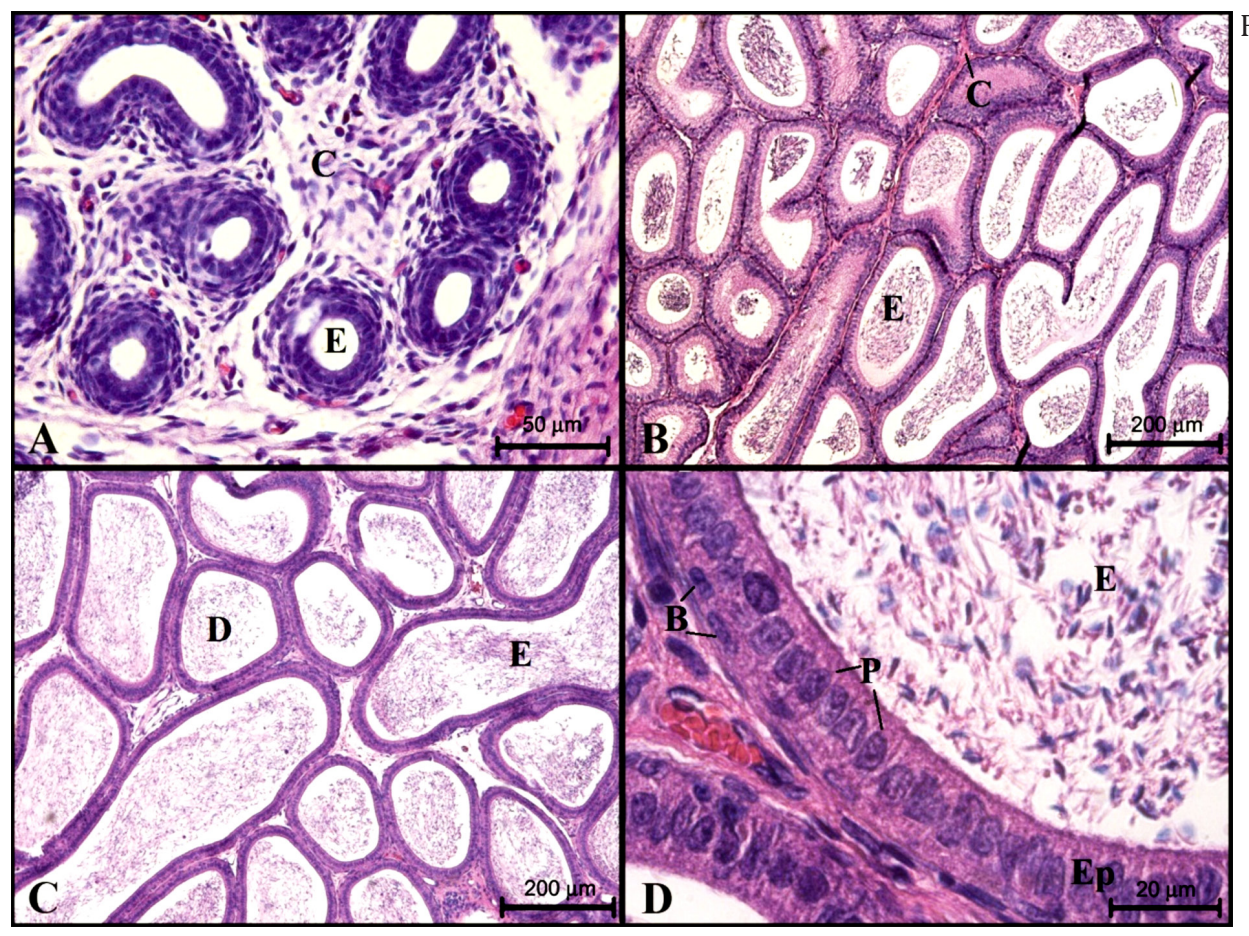

Fig.2. Secções transversais do ducto epidimário do preá em diferentes idades. (A) Ao nascimento, nota-se o tecido conjuntivo (C) no estroma, o lúmen do epidídimo (E) mostra-se pouco desenvolvido e sem presença de espermatozóides, caracterizando a fase impúbere da espécie. (B) 60 dias, nota-se no interstício o tecido conjuntivo (C) e o ducto epidimário desenvolvido com presença de espermatozóides (E), sendo a fase púbere do preá. (C) 120 dias, mostra-se a fase pós-púbere do preá, com desenvolvimento completo do ducto epidimário (D) repleto de espermatozóides (E). (D) 120 dias, observa-se uma porção do epitélio do ducto epidimário com presença das células principais (P) e basais (B), compondo o epitélio colunar simples (Ep). Coloração HE.

Fig.3. Secções transversais do ducto deferente do preá em diferentes idades. Observa-se a mucosa do ducto pregueada envolta por uma camada muscular interna (i) e outra camada mais externa (e) disposta longitudinalmente. (A) 60 dias, o lúmen do ducto (D) mostra-se pouco desenvolvido com pregueamento do epitélio evidente (Ep). (B) 90 dias, o epitélio do ducto deferente mostra-se com um maior desenvolvimento, mostrando uma abertura do pregueamento do epitélio (Ep). (C) 150 dias, mostra-se a fase pós-púbere do preá. 0 lúmen do ducto mostra-se mais desenvolvido e nota-se a presença de espermatozóides (E). (D) 150 dias, observa-se uma porção do epitélio do ducto deferente com as células principais (P) e basais circulares (B), compondo o epitélio colunar pseudo-estratificado (Ep). Coloração HE.

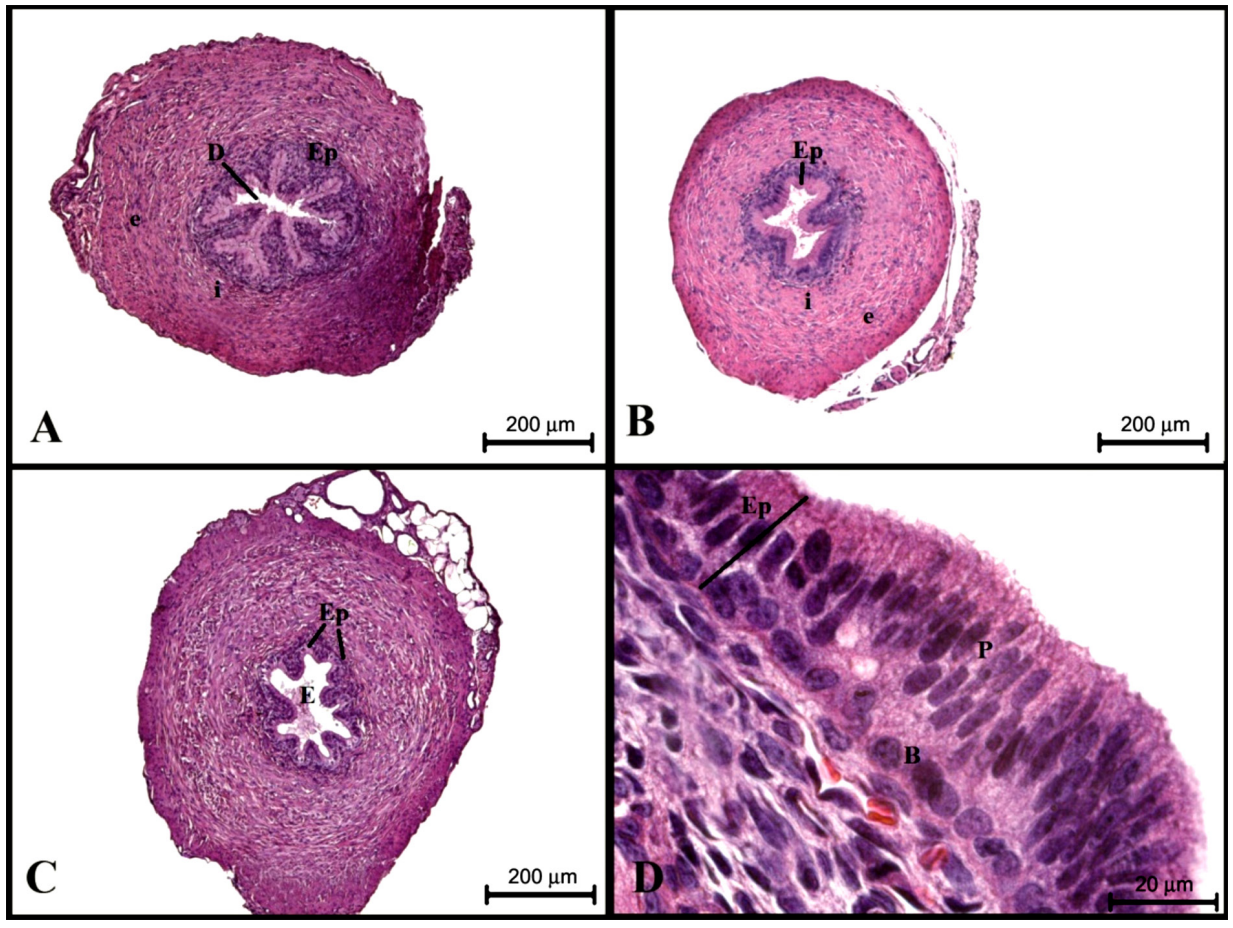

lar, mostram um núcleo alongado e com aspecto granuloso. As células basais se encontram na membrana basal do epitélio do ducto epidimário, subjacentes às células principais, geralmente são pequenas, arredondadas, com um traçado irregular, postas paralelamente à membrana basal (Fig.2D). Um aumento no tamanho epitelial foi observado de acordo com o avanço da fase sexual em que o animal se encontrava: impúbere $(6,06 \pm 2,18 \mu \mathrm{m})$, pré-púbere $(21,44 \pm 2,34 \mu \mathrm{m})$, púbere $(37,91 \pm 2,33 \mu \mathrm{m})$ e pós-púbere $(61,88 \pm 2,33 \mu \mathrm{m})$ e aos 45 dias de idade ficou evidenciado a fase púbere do animal com o aparecimento de espermatozóides (Fig.2).
Ducto deferente. No ducto deferente do preá observou-se epitélio pseudo-estratificado colunar estereociliado apoiado sobre uma lâmina basal seguida por tecido conjuntivo frouxo. Ao longo do desenvolvimento foram visualizados septos direcionados para o lúmen com aspecto pregueado da mucosa emitidos pelo epitélio. 0 epitélio apresentou células variando de altas e baixas. As células principais apresentavam núcleo alongado com citoplasma claro. As células basais apresentavam formato arredondado e citoplasma semelhante (Fig.3D). Aos 45 dias foram observados espermatozóides no lúmen do ducto (Fig.3C). 
Fig.4. Secções da glândula vesicular do preá em diferentes idades. Observa-se a mucosa sobre uma camada de tecido conjuntivo entremeado com tecido muscular liso (m). (A) 30 dias, nota-se um leve pregueamento do epitélio glandular (Ep) e presença de secreção (s) no lúmen da glândula. (B) 75 dias, o epitélio mostra-se com uma maior disposição no pregueamento. (C) 90 dias, mostra-se a fase púbere do preá, com o epitélio (Ep) pregueado e secreção (s) no lúmen glandular. (D) 90 dias), nota-se o pregueamento variável da mucosa sobre uma camada de tecido conjuntivo entremeado com camada muscular lisa (m) e nota-se um epitélio pseudo-estratificado colunar (Ep) e secreção (s) no lumen glandular. Coloração HE.

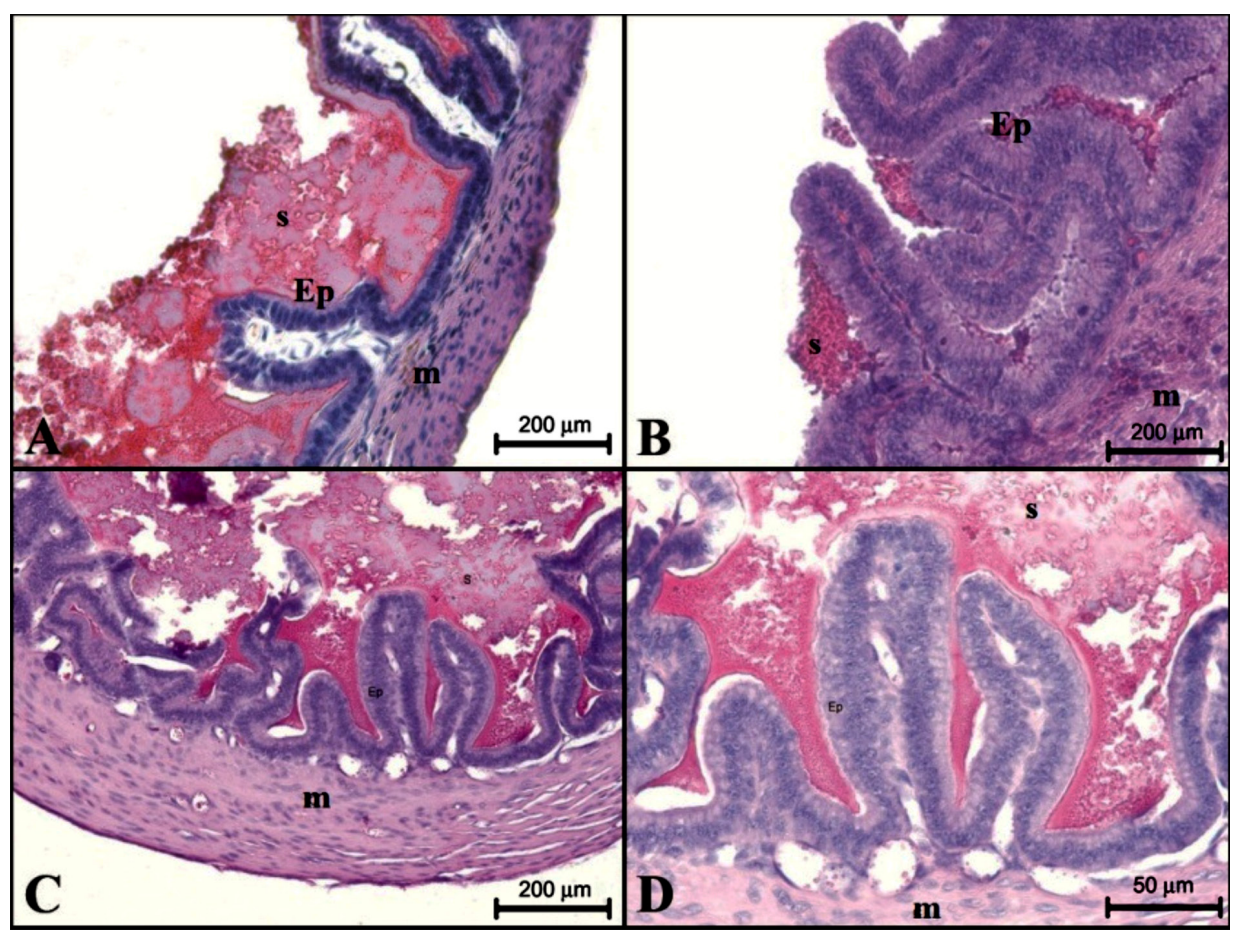

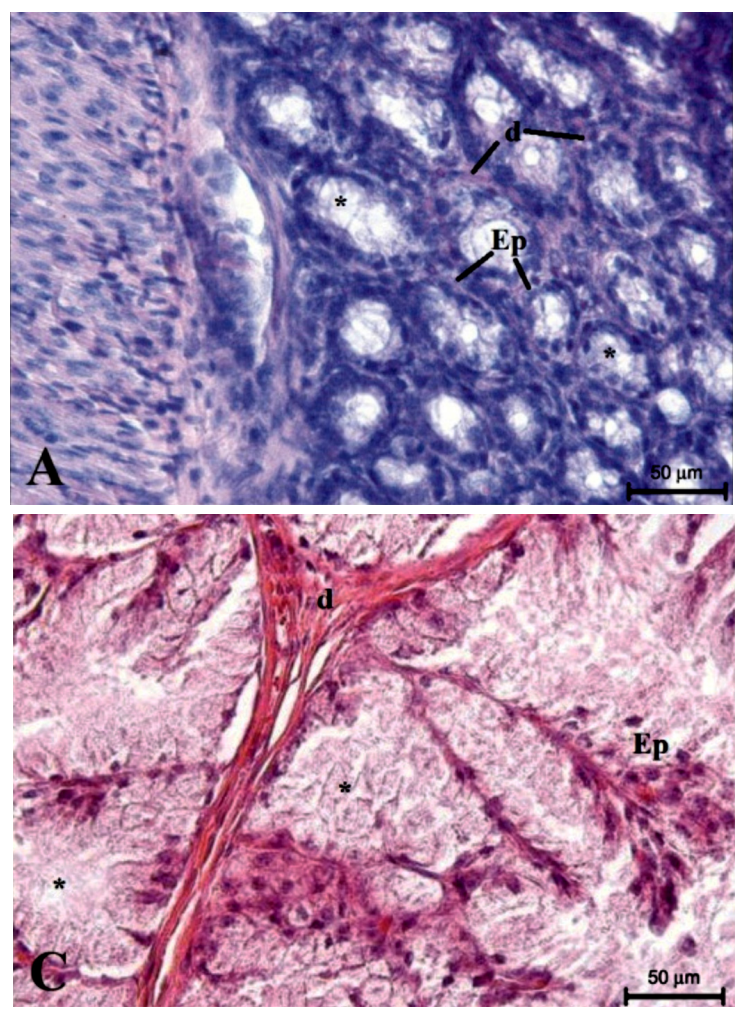

Este lúmen era circundado por duas camadas de tecido muscular. A camada mais interna era disposta de forma longitudinal e externa apresentava orientação circular (Fig.3). Nesta idade ficou evidenciado a entrada do animal na fase de puberdade.

Glândula vesicular. Na glândula vesicular do preá verificou-se um epitélio pseudo-estratificado colunar apoiado sobre tecido conjuntivo frouxo entremeado com tecido

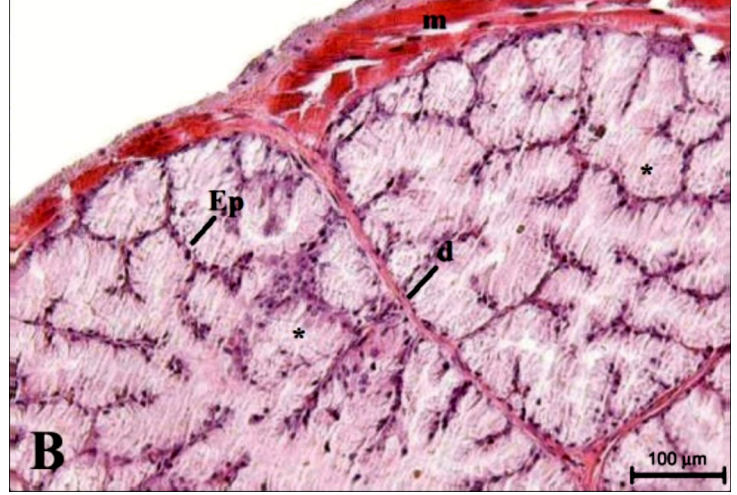

Fig.5. Corte transversal da glândula bulbouretral do preá em diferentes idades. 0 tecido conjuntivo frouxo emite septos que separam os túbulos glandulares (d), envolto por uma camada de tecido muscular esquelético (m). Observa-se também que os núcleos do epitélio simples colunar (Ep) mostram-se arredondados e se localizam basalmente nos túbulos glandulares ( $\left.{ }^{*}\right)$. (A) 0 dia, (B) 2 anos, (C) 2 anos. Coloração HE.

muscular liso. Esta glândula era constituída por túbulos com pregueamento variável (Fig.4). A partir de 30 dias de idade as glândulas vesiculares já apresentavam secreções no lúmem glandular (Fig.4D).

Glândula bulbouretral. A glândula bulbouretral do preá era do tipo túbulo-alveolar, mostrando um epitélio simples colunar (Fig.5). Entre os túbulos foi observado tecido conjuntivo frouxo. Aos 45 dias foi notado que ocorre 


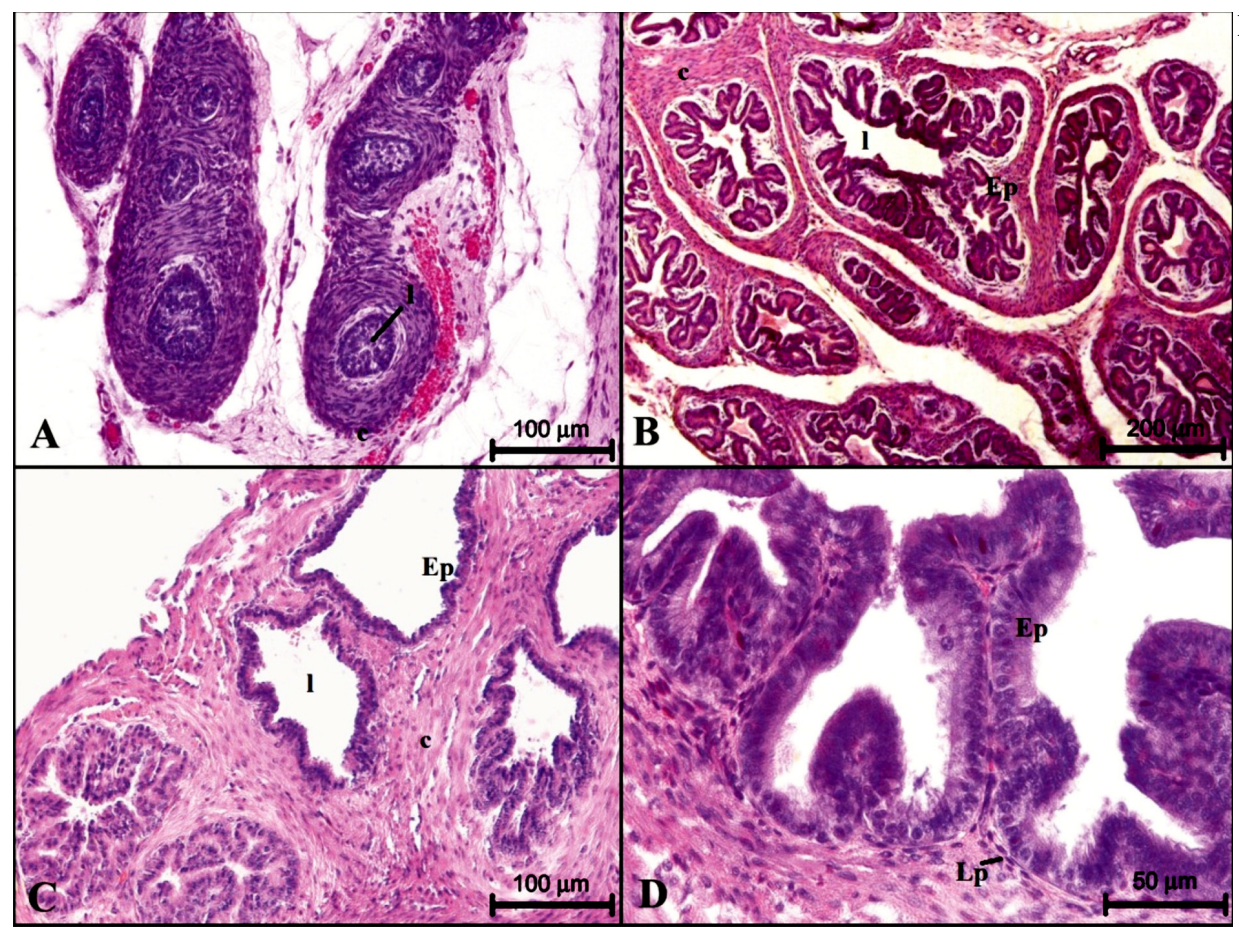

Fig.6. Secções transversais da glândula prostática do preá em diferentes idades. (A) Ao nascimento, nota-se o tecido conjuntivo denso no estroma (c), o lúmen (l) da próstata mostra-se pouco desenvolvido e sem presença de secreção, sendo a fase impúbere da espécie. (B) 30 dias, nota-se no interstício o tecido conjuntivo (c) e a glândula prostática mais desenvolvida no lúmen (l) e um epitélio pregueado (Ep). (C) 75 dias, mostra-se a fase púbere do preá, com desenvolvimento da mucosa glândular (Ep). (D) 75 dias, observa-se uma porção da glândula prostatica composta pelo o epitélio pseudo-estratificado (Ep) apoiado sobre a lâmina própria (Lp). Coloração HE.
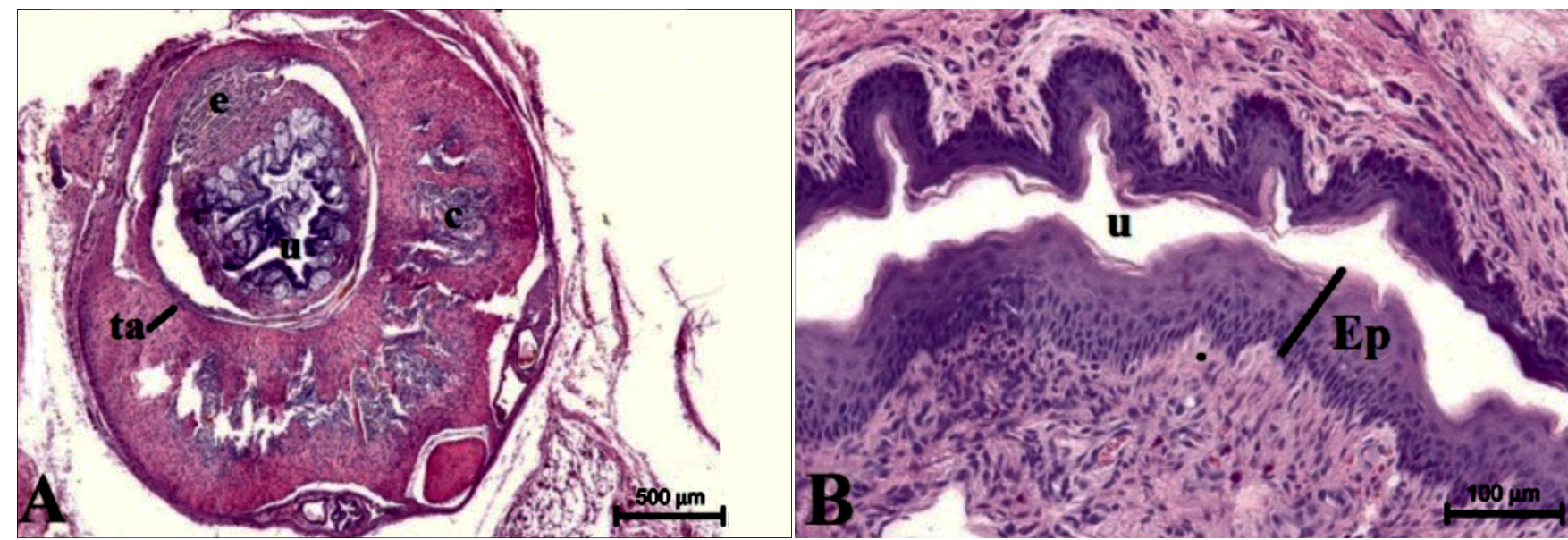

Fig.7. Secções do corpo do pênis do preá aos 30 dias de idade. (A) Observa-se o corpo cavernoso (c) rodeado de tecido conjuntivo denso; nota-se também o corpo esponjoso (e), próximo à uretra (u) e circundado pela túnica albugínea (ta). (B) Nota-se o epitélio de transição (Ep) da uretra peniana. Coloração HE.

um crescimento macroscópico do tecido glandular. 0 citoplasma era pouco corado e vacuolizado, os núcleos estavam localizados basalmente em todas as fases do desenvolvimento reprodutivo.

Próstata. Na próstata do preá observou-se um epitélio era pseudo-estratificado colunar em todas as idades analisadas (Fig.6D). Este apresentada altura epitelial e pregueamento variados e estava apoiado sobre uma camada fibromuscular. Foi evidenciada uma distensão maior do lúmen aos 45 dias quando o animal entra na puberdade (Fig.6).

Pênis. 0 Pênis do preá era formado por uma cápsula de tecido conjuntivo denso que constituía a túnica albugínea do tecido erétil do corpo cavernoso. Observou-se que ao redor da uretra existia menor quantidade de tecido erétil. O corpo esponjoso da uretra era envolto por uma camada de tecido conjuntivo denso a exemplo do corpo cavernoso
(Fig.7A). Foi visualizado epitélio de transição na uretra peniana (Fig.7B).

\section{DISCUSSÃO}

Os órgãos genitais masculinos dos roedores estão representados por um par de testículos, epidídimo, ducto deferente, as glândulas genitais acessórias, o pênis, o prepúcio e o escroto (Menezes et al. 2001). As glândulas sexuais acessórias da maioria dos mamíferos incluem a glândula vesicular, glândula coaguladora, próstata e as glândulas bulbouretrais, contudo nem todas as glândulas sexuais acessórias estão presentes nas espécies de mamíferos (Mollineau et al. 2009). A organização morfológica dos órgãos genitais masculinos do preá se assemelha a disposição e a localização das encontradas em outras espécies de roedores. Nos preás impúberes os órgãos genitais masculinos estão 
pouco desenvolvidos. Os testículos são pequenos com o epidídimo aderido, um ducto deferente retilíneo e pequena proporção das glândulas acessórias. Ao Atingir a puberdade aos 45 dias, o testículo mostra-se os túbulos seminíferos formados com as diferentes células da linhagem espermatogênica e espermatozóides presente no lúmen tubular (Santos et al. a ser publicado), o epidídimo mostra-se em atividade de condução, armazenamento e maturação dos espermatozóides, o ducto deferente apresentou-se como um canal de transporte dos espermatozóides na emissão da ejaculação, e as glândulas acessórias mostraram-se em atividade secretória.

Epidídimo. A histologia do ducto epidimário do preá nas fases impúbere e pré-púbere demonstra que este é revestido por um epitélio colunar simples, mostrou um lúmen pouco desenvolvido $(15,57 \pm 8,32 \mu \mathrm{m})$ e não foi notada a presença de espermatozoides. Para o preá púbere foi observado o mesmo epitélio, mas com um maior desenvolvimento do lúmen tubular $(39,71 \pm 6,85 \mu \mathrm{m})$ o que favorece a maturação e armazenamento dos espermatozóides (Lorenzana et al. 2007).0 epitélio colunar simples foi visto para a espécie Cuniculus paca na região da cauda do epidídimo; este também foi observado no ducto epidimário do rato gigante da Índia (Amiya \& Maiti 1982), no hamster dourado (Nicander \& Glover 1973), rato mexicano (Lorenzana et al. 2007) e no rato (Abe et al. 1982).

Ducto deferente. 0 epitélio do ducto deferente no preá mostrou-se pseudo-estratificado colunar com crescente presença de estereocilios com o avanço da idade, apresentando semelhanças ao rato gigante da Índia (Amiya \& Maiti 1982), no rato (Niemi 1965), quati (Franciolli et al. 2007), espécies em que o epitélio também identificado como pseudo-estratificado com estereocilios proeminentes. 0 epitélio do ducto deferente preá mostrou dois tipos celulares, as células principais e as basais, ambas apresentando citoplasma claro, diferindo-se pela forma de seus núcleos, as primeiras mostraram um núcleo alongado, enquanto as basais seus núcleos eram arredondados. De forma semelhante estes tipos celulares foram descritos por Sprando et al. (1999) no rato de areia. Dando sustentação ao epitélio, havia tecido conjuntivo entremeado por duas camadas de músculo liso, uma delgada camada longitudinal externa e uma circular interna mais espessa que a primeira; sendo que esta disposição foi observada em ratos por Kennedy \& Heider Jr (1979).

Glândula vesicular. A glândula vesicular no preá apresentou uma mucosa pregueada com alta variação, de acordo com a fase do desenvolvimento sexual. As dobras davam um aspecto de vilosidades, mesmo modo visto no rato gigante da Índia por Amiya \& Maiti (1982), sendo que esses vilos estavam voltados para o interior da luz do órgão. 0 epitélio em preás apresentou ser pseudo-estratificado colunar, assemelhando-se a outras espécies como a viscacha (Chaves et al. 2011); cutia (Menezes et al. 2010, Mollineau et al. 2009), rato gigante da Índia (Amiya \& Maiti 1982), o rato (Gude et al. 1982), o rato de laboratório (Hebel \& Stromberg 1986) o rato de areia (Sprando et al 1999), e paca (Matamoros 1981).

Glândula bulbouretral. As glândulas bulbouretrais do preá são envoltas por um músculo estriado esquelético semelhante a outras espécies de roedores (Gude et al. 1982, Hebel \& Stromberg 1986). O músculo mostrou-se associado ao tecido conjuntivo denso, o qual emitia septos ao parênquima glandular dividindo-o em lóbulos que eram constituídos por tecido glandular do tipo túbulo-alveolar, esta disposição foi observada aos 45 dias de idade, quando o animal entrou na puberdade. 0 mesmo tecido do tipo túbulo-alveolar e epitélio simples colunar também foi observado no rato por Gude et al. (1982), por Amiya \& Maiti (1982) no rato gigante da Índia, na viscacha (Chaves et al. 2011), e em cutias (Mollineau et al. 2009, Menezes et al. 2010).

Próstata. A próstata mostrou-se pouco desenvolvida nos preás ao nascimento e aos 15 dias de idade notou-se um lúmen pequeno e com o epitélio sem pregueamento. Ao atingir a puberdade, aos 45 dias, a próstata do preá mostrou-se com um lúmen desenvolvido e com um pregueamento do epitélio variável. A mucosa dos ductos prostáticos era do tipo pseudo-estratificado, assemelhando com o rato de laboratório (Hebel \& Stromberg 1986), viscacha (Chaves et al. 2011), e a cutia (Mollineau et al. 2009, Menezes et al. 2010).

Pênis. Histologicamente o pênis do preá apresentou uma estrutura que se assemelha ao da paca (Borges 2004), quati (Franciolli et al. 2007) e ao da cutia (Menezes 2003), constituído por uma camada de tecido conjuntivo denso compondo a túnica albugínea do corpo esponjoso e corpo cavernoso. 0 epitélio que revestia a uretra, no preá, era do tipo de transição, o mesmo observado na uretra do rato por Junqueira e Martins (1974).

Os órgãos genitais masculinos do preá passaram por transformações morfológicas com o desenvolvimento sexual do animal. Este estudo foi importante para determinar a fase do início da puberdade que nesta espécie ficou evidenciada aos 45 dias de idade, quando são observados espermatozóides no lúmen do epidídimo e ducto deferente.

Agradecimentos.- Ao MSc. Marcio N. Rodrigues pela colaboração durante a coleta do material. À Fundação de Amparo e Pesquisa do Estado de São Paulo (FAPESP, processos 08/57190-8 e 10/14516-0) pelo apoio financeiro para a realização deste estudo e ao Centro de Multiplicação de Animais Silvestres da Universidade Rural do Semiárido (Ufersa-RN) por terem cedido os animais utilizados nesta pesquisa.

\section{REFERÊNCIAS}

Abe K., Takano H. \& Ito T. 1982. Response of the, epididymal duct in the corpus epididymidis to efferent of epididymal duct ligation in the mouse. J. Reprod. Fertil. 64(1):69-72.

Amiya P.S.H. \& Maiti B.R. 1982. Quantitative studies of the reproductive organs of the male bandicoot rat - A common rodent pest. Ann. Anat. 151(5)5:483-495.

Borges E.M. 2004. Morfologia dos órgãos genitais masculinos da paca (Agouti paca Linnaeus, 1766). Tese de Doutorado em Ciências, Faculdade de Medicina Veterinária e Zootecnia, Universidade de São Paulo, São Paulo. 165p.

Chaves E.M., Aguilera-Merlo C., Filippa V., Mohamed F., Dominguez S. \& Scardapane L. 2011. Anatomical, histological and immunohistochemical study of the reproductive system accessory glands in male viscacha ( $L a-$ gostomus maximus maximus). Anat. Histol. Embryol. 40:11-20.

Eisenberg J.F. \& Rerdford K.H. 1999. Mammals of the Neotropics: The Cen- 
tral Neotropics. Vol.3. Ecuador, Peru, Bolivia, Brazil. University of Chicago Press, Chicago. 609p.

Franciolli A.L.R., Costa G.M., Mançanares C.A.F., Martins D.S., Ambrósio C.E., Miglino M.A. \& Carvalho A.F. 2007. Morfologia dos órgãos genitais masculinos de quati (Nasua nasua Linnaeus, 1766). Biotemas 20 (1):27-36.

Gude W.D., Cosgrove G.E. \& Hirsch G.P. 1982. Histological Atlas of the Laboratory Mouse. Plenum Press, New York, p.70-79.

Hebel R. \& .Stromberg M.V. 1986. Anatomy and Embriology of the Laboratory Rat. BioMed Verlag, Wörthesee. 270 p.

Hoffer A.P. \& Greenberg J. 1978. The structure of the epididymis, efferent ductules and ductus deferens of the guinea pig: A light microscopia study. Anat. Rec. 190(3):659-678.

International Committee on Veterinary Histological Nomenclature 1994. Nomina Histological. $3^{\mathrm{a}}$ ed. Word Association on Veterinary Anatomists, Züurich, Switzerland. 405p.

Kennedy S. \& Heidger Jr P.M. 1979. Fine structural studies of the rat vas deferens. Anat. Rec. 194(1):159-180.

Lorenzana M.G., Lopez-Wilchis R., Gomez C.S. \& Aranzabal M.C.U. 2007. A Light and Scanning Electron Microscopic Study of the Epididymis Active State of the Endemic Mexican Rodent Peromyscus winkelmanni (Carleton) (Rodentia: Muridae). Anat. Histol. Embryol. 36:230-240.

Matamoros Y. 1981. Anatomia e histologia dei sistema reproductor dei tepezcuinte (Cunicullus paca). Revta Biol. Trop., San Jose, 29(1):155-164.

Mendes B.V. 1987. Plantas e Animais para o Nordeste. Globo, Rio de Janeiro. $167 \mathrm{p}$.

Menezes D.J.A. 2001. Morfologia dos órgãos genitais masculinos da cutia (Dasyprocta aguti Linnaeus, 1766). Dissertação de Mestrado em Anatomia, Faculdade de Medicina Veterinária e Zootecnia, Universidade de São Paulo, São Paulo. 169p.

Menezes D.J.A., Carvalho M.A.M., Assis Neto A.C., Oliveira M.F., Farias E.C., Miglino M.A. \& Medeiros G.X. 2003. Morphology of the external male genital organs of agouti (Dasyprocta aguti Linnaeus, 1766). Braz. J. Vet. Res. Anim. Sci. 40:148-153.
Menezes D.J.A., Assis Neto A.C., Oliveira M.F., Miglino M.A., Pereira G.R., Ambrósio C.E., Ferraz M.S. \& Carvalho M.A.M. 2010. Morphology of the male agouti accessory genital glands (Dasyprocta prymnolopha Wagler, 1831). Pesq. Vet. Bras. 30(9):793-797.

Mollineau W.M., Adogwa A.O. \& Garcia G.W. 2009. The gross and micro anatomy of the accessory sex glands of the male agouti (Dasyprocta leporina). Anat. Histol. Embryol. 38:204-207.

Nicander L. 1956. On the regional histology and cytochemistry of the ductus epididymidis in rabbits. Acta Morphol. Neerl. Scand. 1:99-118.

Nicander L. \& Glover T.D. 1973. Regional histology and fine structure of the epididymal duct in the golden hamster (Mesocricetus auratus). J. Anat. 114(3):347-364.

Niemi M. 1973. The fine structure and histochemistry of the epithelial cells of the rat vas deferens. Acta Anat. 60(1):207-219.

Oliveira M.F., Mess A., Ambrósio C.E., Dantas A.G., Favaron P.O. \& Miglino M.A. 2008. Chorioallantoic placentation in Galea spixii (Rodentia, Caviomorpha, Caviidae). Reprod. Biol. Endocrinol. 6:39. doi: 10.1186/14777827-6-39.

Paes de Barros M.A.F., Rondon A.S., Persona L.N. \& Simões M.J. 2000. Morfologia microscópica do epidídimo de capivara Hidrochoerus hidrochaeris. Braz. J. Morphol. Sci. 17:158.

Santos P.R.S., Carrara T.V.B., Silva L.C.S., Silva A.R., Oliveira M.F. \& Assis Neto A.C. 2011. Morphological characterization and frenquency of stages of the seminiferous epithelium cycle in captive bred Spix's Yellow-Toothed (Galea spixii Wagler, 1831). Pesq. Vet. Bras. 31(1):1824.

Santos P.R.S., Oliveira M.F. \& Assis Neto A.C. 2012. Development of spermatogenesis in captive bred spix's yellow-toothed (Galea spixii Wagler, 1831). Reprod. Fertil. Dev. 24(6):877-885.

Sprando R.L., Collins T.F.X., Black T.N., Olejnik N., Rorie J.L., West L.J., Bowers J.D. \& Sass N. \& Robl M. 1999. Light microscopic observations on the reproductive tract of the male sand rat, Psammomys obesus. Tissue Cell 31(1):99-115. 